\title{
Immunohistochemical profiling of node negative breast carcinomas allows prediction of metastatic risk
}

\author{
SOPHIE GIUSIANO ${ }^{1,2}$, VERONIQUE SECQ ${ }^{1,2}$, XAVIER CARCOPINO $^{3}$, SEVERINE CARPENTIER $^{1}$ \\ LUCILE ANDRAC $^{1}$, MARIE-NOELLE LAVAUT ${ }^{1}$, CLAUDE ALLASIA ${ }^{1}$, PASCAL BONNIER ${ }^{3}$, \\ JUAN LUCIO IOVANNA ${ }^{2}$, STEPHANE GARCIA ${ }^{1,2}$, LEON BOUBLI ${ }^{3}$, \\ DANIEL BIRNBAUM ${ }^{4}$ and COLETTE CHARPIN ${ }^{1,2}$ \\ ${ }^{1}$ Department of Pathology, Hôpital Nord and Université de la Méditerranée; ${ }^{2}$ INSERM UMR 624, \\ Université de la Méditerranée, Luminy; ${ }^{3}$ Departments of Gynecologic Oncology, Hôpital Nord \\ et Hôpital de la Conception; ${ }^{4}$ INSERM UMR 891, Institut Paoli Calmettes, Marseille, France
}

Received November 2, 2009; Accepted December 23, 2009

DOI: 10.3892/ijo_00000567

\begin{abstract}
The aim of this study was to identify a prognostic immunohistochemical signature indicative of risk of early metastasis in node-negative breast carcinomas that would also be relevant to the development of new tailored therapy. Quantitative measurements of the immunohistochemical expression of 64 markers (selected from literature data) using high-throughput densitometry (as a continuous variable) of digitised microscopic micro-array images were correlated with clinical outcome in 667 node-negative breast carcinomas (mean follow-up 102 months). Multivariable fractional polynomials model of logistic regression allowed the selection of the best combination of markers (in terms of sensitivity and specificity) to predict patient outcome without any categorisation using predefined cut-points for individual marker measurements. A highly predictive ten-marker (out of 64) signature was identified comprising PI3K, pmTOR, pMAPKAPK-2, SHARP-2, P21, HIF-1 $\alpha$, Moesin, p4 ${ }^{\mathrm{E}} \mathrm{BP}-1$, pAKT and P27 that well classified $91.4 \%$ of node-negative patients (specificity $90.9 \%$, sensitivity $93.7 \%$, area under ROC curve 0.958 ) independently of estrogen receptors (ER), and progesterone receptors (PR) and HER-2 status (91.6\% well classified patients when ER, PR, HER-2 excluded). It is concluded that quantitative immunoprofiling of node-negative breast carcinomas is helpful in selecting patients who should not receive aggressive adjuvant chemotherapy and provides data for the development of tailored therapy.
\end{abstract}

Correspondence to: Professor Colette Charpin, Hôpital Nord, Service d'Anatomie Pathologique, Chemin des Bourrelly, 13915 Marseille Cedex 20, France

E-mail: colette.charpin@ap-hm.fr

Key words: quantitative immunohistochemical profiling, nodenegative breast carcinoma, tissue micro-arrays, multivariable fractional polynomials logistic regression

\section{Introduction}

The incidence of early-stage breast carcinomas, particularly lymph node-negative cases, has increased with the implementation of breast cancer screening programs in Western countries. Patients with node-negative breast cancer have a fairly good ten-year overall survival with loco-regional treatment alone, only 30-40\% developing distant metastases (1). However, most patients are offered chemotherapy according to current guidelines, leading to over-treatment of a large proportion $(2,3)$, since there is no means of clearly identifying those patients who will not relapse and hence do not need adjuvant chemotherapy. Therefore, markers to identify patients not requiring aggressive adjuvant therapy are urgently needed, so as to avoid unnecessary exposure of women to the potential toxicity and side-effects of such treatment, and also to reduce the overall cost of breast cancer management.

The development of high-throughput techniques such as gene expression profiling has significant potential for the identification of prognostic classifiers (4-10). Several studies have reported gene signatures predictive of prognosis in nodenegative breast carcinomas (11-13). However, these assays i) usually require frozen tissue, and this sampling can be detrimental to pathological diagnosis in small tumours, and ii) large amount of data provided by gene expression microarrays may be somewhat liable to misinterpretation or poorly validated (14-16).

In contrast, immunohistochemical assays require only a small amount of tissue easily obtained from paraffin blocks used for diagnosis, and can be standardised by quantification of immunoprecipitates and automated devices (17-21). Our objective was to identify an immunohistochemical signature of poor prognosis (risk of early distant metastasis), in cases of node-negative breast carcinoma, which would be economically acceptable. For this purpose, we assessed 64 markers (a large panel of known prognostic markers of tumour cell growth and proliferation, invasion and scattering, and angiogenesis, in addition to markers of signaling pathways) by standardised quantitative immunohistochemistry (IHC). We used the 
SAMBA/TRIBVN device (22-28) that provides accurate numerical data for statistical analysis of continuous variables, with high-throughput assays using TMAs (29-41) in a large retrospective series $(n=667)$ of node-negative breast carcinomas. We have recently reported our experience with this standardised method for quantifying immunoprecipitates $(42,43)$, which proved to be of potential clinical relevance through identification of immunohistochemical signatures of prognosis. However, methods relying upon dichotomising continuous predictors $(42,43)$, using cut-points in logistic regression are controversial $(14-15,44,45)$. Therefore, in the present study, we correlated the quantified immunohistochemical expression of each marker, then of groups of markers (referred to as immunohistochemical signatures), with the patient outcome (mean follow-up 102 months), in order to identify the combination of markers with the best sensitivity and specificity to predict prognosis in terms of occurrence of early distant metastases, using a multivariable fractional polynomials method $(46,47)$. This approach allowed us the use continuous values of variables (densitometry of markers immunoexpression) so that the correlation between a continuous predictor and the outcome variable could be evaluated in some form of non-linearity.

\section{Materials and methods}

Patients. We studied a consecutive series of 667 patients with invasive breast carcinomas who were operated from 1996 to 2002 in the same departments at the Conception and Nord hospitals in Marseille. Surgery was in all cases the first treatment. For this first step of treatment, patient management was handled by the same group of surgeons (PB, LB and $\mathrm{XC}$ ), and the diagnosis was assessed by three senior pathologists (CC, SG and LA). Conservative treatment and node resection (complete or sentinel) were applied according to current European recommendations. Likewise, radiotherapy, chemotherapy and hormone therapy were applied according to criteria used at that time.

Due to technical difficulties in performing IHC tests on many serial paraffin sections of a TMA to evaluate the 64 different markers, complete data for all markers were eventually obtained for only 572 patients out of the initial series of 667. The 2007 follow-up data in clinical records (mean follow-up 102 months from 1996 to 2007) showed that 111 of 572 patients had distant metastases. The age of patients at diagnosis ranged from 40 to 65 (mean 57) years. Briefly, tumours were pT1b (32\%) and pT1c (68\%). All were invasive ductal carcinomas not otherwise specified and $29 \%$ were grade 1, 59\% grade 2 and $12 \%$ grade 3 (Ellis and Elston grading method).

Our study focused mainly on correlation of quantitative immunohistochemical data with the patient outcome, independently of pT and tumour grade. Therefore, current histoprognostic data were not retained for statistical analysis, mainly to limit the burden of data and also to focus on the statistical analysis on continuous variables homogeneously obtained by (numerical) densitometric measurements of immunoprecipitates obtained with the image analyser.
Tissue. Tissue samples were all taken from surgical specimens after formalin fixation. Attention was paid to optimal and consistent tissue-handling procedures, including fast immersion in buffered formalin in an appropriate container by pathologists or by nurses trained in the procedure. Tumour samples were large and thick enough to allow subsequent TMA construction. Duration of fixation was $24 \mathrm{~h}$ for smaller resections $(<5 \mathrm{~cm})$ and $48 \mathrm{~h}$ for larger ones, to improve formalin penetration, before specimen dissection at room temperature. After fixation, paraffin pre-embedding and embedding were performed with currently available automated devices of the same brand. All paraffin blocks were stored in the same room, where the temperature was maintained at $20^{\circ} \mathrm{C}$ prior to TMA construction.

TMA construction. The procedure for construction of TMAs was as previously described $(22,27,28,42,43)$. Briefly, cores were punched from the selected 667 paraffin blocks, and distributed in three new blocks including two cores of $0.6 \mathrm{~mm}$ diameter for each tumour (about 220 cases per block). All the TMAs blocks were stored at $4^{\circ} \mathrm{C}$.

Immunohistochemistry. Serial tissue sections were prepared $24 \mathrm{~h}$ before immunohistochemical processing and stored at $4^{\circ} \mathrm{C}$, as previously reported $(22-28,42,43)$. The immunoperoxidase procedure was performed using an automated Ventana Benchmark XT device which allowed similar well controlled antigen retrieval for all tumours, and Ventana kits. Markers were detected using 64 commercially available and documented antibodies (except anti-HIF-1 $\alpha$ kindly provided by Dr R. Pouyssegur, Nice, France). Antibodies are listed in Table I. Dilutions of each antibody were determined by prescreening on the full $4 \mu \mathrm{m}$ thick sections before use on TMA sections.

Image analysis. Densitometric measurements of immunoprecipitates in cores were assessed for each marker antibody in each individually identified core after digitization and cropping of the slide images, as previously reported $(27,28,40)$ with a SAMBA 2050 automated device (SAMBA/TRIBVN Technologies, France).

Statistical analysis. Immunohistochemical expression of each marker was first correlated with disease-free survival using NCSS and Statistica statistical software (available on line). When significant differences in mean quantitative scores of expression were identified between patients with or without distant metastasis or death (Mann-Whitney tests), the prognostic relevance was re-evaluated for each marker using log-rank test (Kaplan-Meier curves). The distribution and relationship of prognostic markers were then documented through supervised hierarchical clusters and dendrograms, as previously reported $(27,28,42,43)$.

Importantly we used logistic regression (and ROC curves) to identify the combination of markers (referred to as 'signature') with the best sensitivity and specificity for prediction of prognosis. The method of multivariable fractional polynomials was used to correlate the outcome variable with the quantitative IHC expression of markers as continuous variables without predetermined cut-points $(44,46,47)$. 


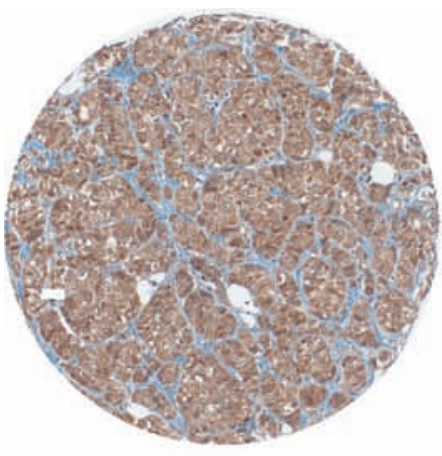

$\mathrm{PI} 3 \mathrm{~K}$
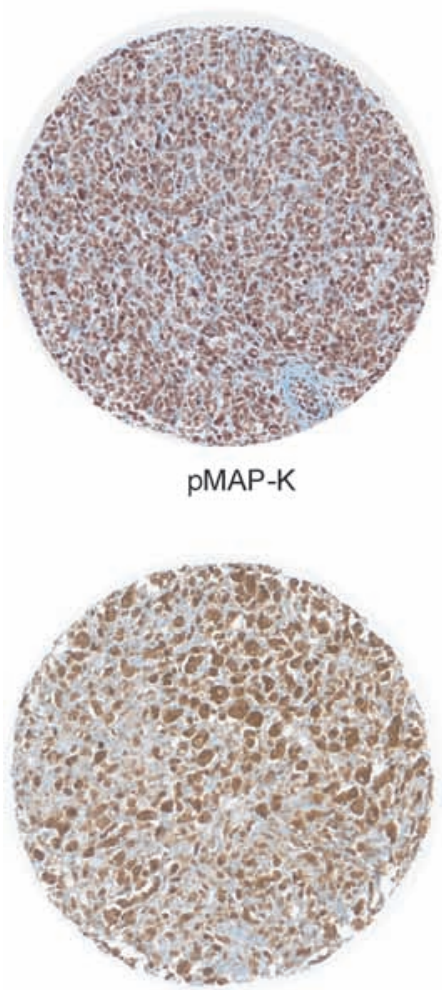

p4E-BP1
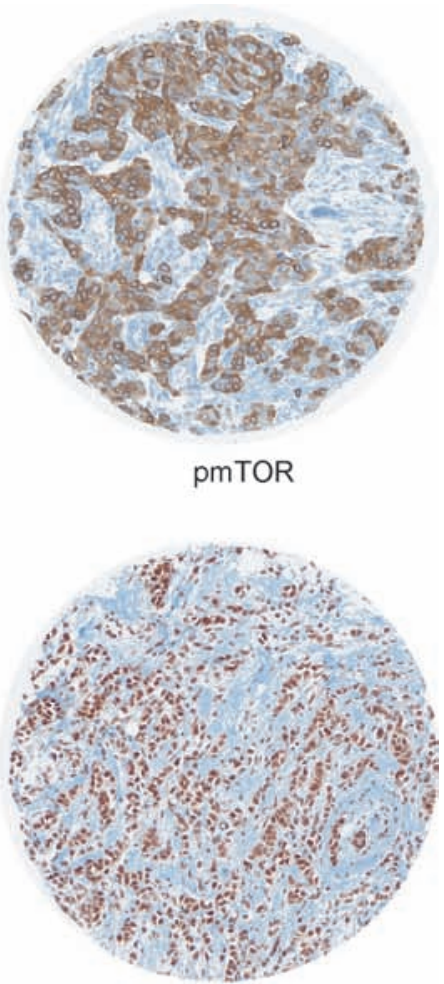

HIF-1 $\alpha$

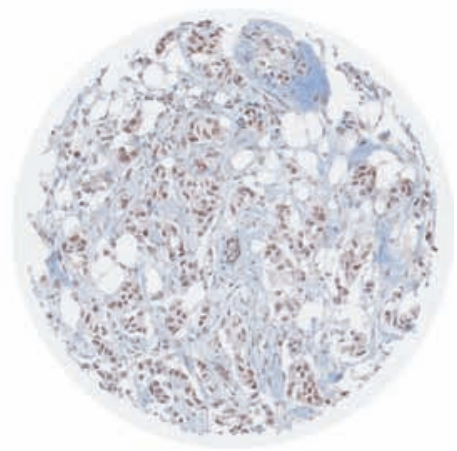

PAKT

Figure 1. Individual core immunostaining in TMA of node negative breast carcinomas illustrating the immunoreactions with 6 of the 10 markers included (PI3K, pmTOR, pMAPKAPK-2, HIF-1 $\alpha$, p4 $^{\mathrm{E}}-\mathrm{BP}-1, \mathrm{pAKT}$ ) in the prognostic signature.

\section{Results}

Screening of potential markers of prognosis. TMAs containing tumour samples from patients with $(\mathrm{n}=111)$ or without distant metastasis $(n=461)$ were screened for immunoexpression of markers (Table I, Fig. 1). Complete data for all 64 markers were available for 572 tumours (loss of some cores in TMAs occurred for 95 tumours). The prognostic significance of markers, individually evaluated by a univariate log-rank test (Fig. 2) as previously described (22-28,42,43,52,55), served for hierarchical clustering as shown in Fig. 3.

Logistic regression (ROC curves). The relationship between groups of predictive markers and the outcome variable was then evaluated by the multivariable fractional polynomials method $(44,46,47)$, without any cut-point but keeping marker quantitative score values as continuous variables. The optimal combination computered from the image analysis data bank for the 64 markers in 572 node-negative breast carcinomas is shown in Table II and Fig. 4. A ten-marker signature comprising PI3K, pmTOR, pMAPKAPK-2, SHARP-2, P21, HIF-1 $\alpha$, moesin, p4 ${ }^{\mathrm{E} B P}-1, \mathrm{p}$ AKT and P27 was found to well classify $91.4 \%$ of the patients in the category of either unfavorable or favorable prognosis with $93.7 \%$ sensitivity (well classified 104/111) and 90.9\% specificity (well classified 419/461) (Fig. 4).

When the logistic regression was re-assessed (Table II) with exclusion of ER, PR and HER-2 (61 markers instead of 64), the same signature correctly classified patients in $91.61 \%$ of the cases, suggesting that the above set of 10 markers constitutes a significant indicator of prognosis independently of hormone receptor status and HER-2 amplification. When the multivariable fractional polynomials method was used on this series of 572 tumours, the estimated logistic regression 
Table I. Antibodies used in 667 node-negative breast carcinomas (Ventana Benchmark XT automated device, immunoperoxidase).

\begin{tabular}{|c|c|c|c|c|}
\hline & Antibodies & Supplier & Source $^{a}$ & Clone \\
\hline 1 & MMP7 & Abcam & Rpab & \\
\hline 2 & MMP11 & Abcam & Rmab & EP1259Y \\
\hline 3 & Elf4E & Cell signaling & Rmab & C46H6 \\
\hline 4 & P70 S6 Kinase & Cell signaling & Rmab & 49D7 \\
\hline 5 & FOXO3a & Cell signaling & Rpab & \\
\hline 6 & P 42-MAP-Kinase (ERK-2) & Cell signaling & Rpab & \\
\hline 7 & AF6 & BD Biosciences & Rmab & 35 \\
\hline 8 & YB1 & Abcam & Mpab & \\
\hline 9 & Phospho-mTOR (Ser2448) & Cell signaling & Rmab & 49F9 \\
\hline 10 & PTEN & Signet COVANCE & Mmab & $6 \mathrm{H} 2.1$ \\
\hline 11 & VEGF & R\&D Systems & Mmab & 26503 \\
\hline 12 & Phospho-4E-BP-1(Thr37/46) & Cell signaling & Rmab & 236B4 \\
\hline 13 & HIF $1 \alpha$ & Gift $^{\mathrm{b}}$ & Mmab & 729T3 \\
\hline 14 & MDR & Abcam & Mmab & JSB1 \\
\hline 15 & Topoisomerase II $\alpha$ & Dako & Mmab & Ki-S1 \\
\hline 16 & ß-Catenin & Novocastra & Mmab & $17 \mathrm{C} 2$ \\
\hline 17 & GATA-3 & Santa Cruz & Mmab & HG3-31 \\
\hline 18 & FGFR-1 Flg (C-15) & Santa Cruz & Rpab & \\
\hline 19 & Maspin & BD Pharmingen & Mmab & G167-70 \\
\hline 20 & MET & Chemicon/Abcys & Mmab & 4AT44 \\
\hline 21 & P-Cadherin & Novocastra & Mmab & $56 \mathrm{C} 1$ \\
\hline 22 & Ezrin (p81, 80k, cytovillin) & Neomarkers & Mmab & $3 \mathrm{C} 12$ \\
\hline 23 & phospho-AKT (Ser473) & Cell Signaling & Rmab & $587 \mathrm{~F} 11$ \\
\hline 24 & CD 44v6 & Novocastra & Mmab & VFF-7 \\
\hline 25 & CD44 (HCAM) & Novocastra & Mmab & F10-44-2 \\
\hline 26 & Moesin & Biomeda & Mmab & $38 / 87$ \\
\hline 27 & Moesin & Neomarkers & Mmab & $38 / 87$ \\
\hline 28 & Cytokeratins $8-18$ & Zymed & Mmab & (UCD/PR-10,11) \\
\hline 29 & Cytokeratin 17 & Dako & Mmab & E3 \\
\hline 30 & Cytokeratin 14 & Novocastra & Mmab & LL002 \\
\hline 31 & phospho-STAT-3(Tyr705) & Cell Signaling & Rmab & D3A7 \\
\hline 32 & Melan A & Dako & Rmab & A103 \\
\hline 33 & CD 10 & Novocastra & Mmab & $56 C 6$ \\
\hline 34 & CD 34 & Dako & Mmab & QBEnd-10 \\
\hline 35 & Vimentin & Immunotech & Mmab & V9 \\
\hline 36 & Cytokeratin 19 & Dako & Mmab & BA17 \\
\hline 37 & phospho-MAPKAPK-2 & Cell Signaling & Rmab & (Thr334) \\
\hline 38 & EGFR & Ventana & Mmab & 3C6 \\
\hline 39 & STAT-1 & Cell Signaling & Mmab & $9 \mathrm{H} 2$ \\
\hline 40 & FAK & Cell Signaling & Rpab & \\
\hline 41 & P38 MAP-Kinase & Cell Signaling & Rpab & \\
\hline 42 & P27 Kip1 & Cell Signaling & Rpab & \\
\hline 43 & P21Waf1-Cip1 & Cell Signaling & Mmab & DCS60 \\
\hline 44 & SHARP 2 & Abcam & Rpab & \\
\hline 45 & FYN & Abcam & Mmab & $1 \mathrm{~S}$ \\
\hline 46 & P63 & Dako & Mmab & 4A4 \\
\hline 47 & Cytokeratin 903 & Dako & Mmab & 34BE12 \\
\hline 48 & Carbonic anhydrase IX & Abcam & Rpab & \\
\hline 49 & E-Cadherin & Zymed & Mmab & $4 \mathrm{~A} 2 \mathrm{C} 7$ \\
\hline 50 & CD 117 / KIT & Dako & Rpab & \\
\hline 51 & Cytokeratins 5-6 & Dako & Mmab & D5/16B4 \\
\hline 52 & PTEN & Cell Signaling & Mmab & $26 \mathrm{H} 9$ \\
\hline 53 & PI3 Kinase & Cell Signaling & Rpab & \\
\hline
\end{tabular}


Table I. Continued

\begin{tabular}{|c|c|c|c|c|}
\hline & Antibodies & Supplier & Source $^{a}$ & Clone \\
\hline 54 & JAK 1 & Cell Signaling & Rpab & \\
\hline 55 & MET & Novocastra & Mmab & $8 F 11$ \\
\hline 56 & Caveolin 1 & Santa Cruz & Rpab & \\
\hline 57 & CD-105 & Dako & Mmab & SN6h \\
\hline 58 & CD-146 & Novocastra & Mmab & N1238 \\
\hline 59 & BCL-2 & Dako & Mmab & 124 \\
\hline 60 & P53 & Dako & Mmab & DO-7 \\
\hline 61 & P16 & Neomarkers & Mmab & $\mathrm{Ab} 7(16 \mathrm{PO} 7)$ \\
\hline 62 & HER-2 & Novocastra & Mmab & CB11 \\
\hline 63 & PR & Ventana & Mmab & $1 \mathrm{E} 2$ \\
\hline 64 & ER & Ventana & Mmab & $6 \mathrm{~F} 11$ \\
\hline
\end{tabular}

${ }^{\mathrm{a} M m a b}$, mouse monoclonal antibody; Rpab, rabbit polyclonal antibody. ${ }^{\mathrm{b} K i n d l y ~ p r o v i d e d ~ b y ~ P o u y s s e g u r ~ e t ~ a l ~(51) . ~}$
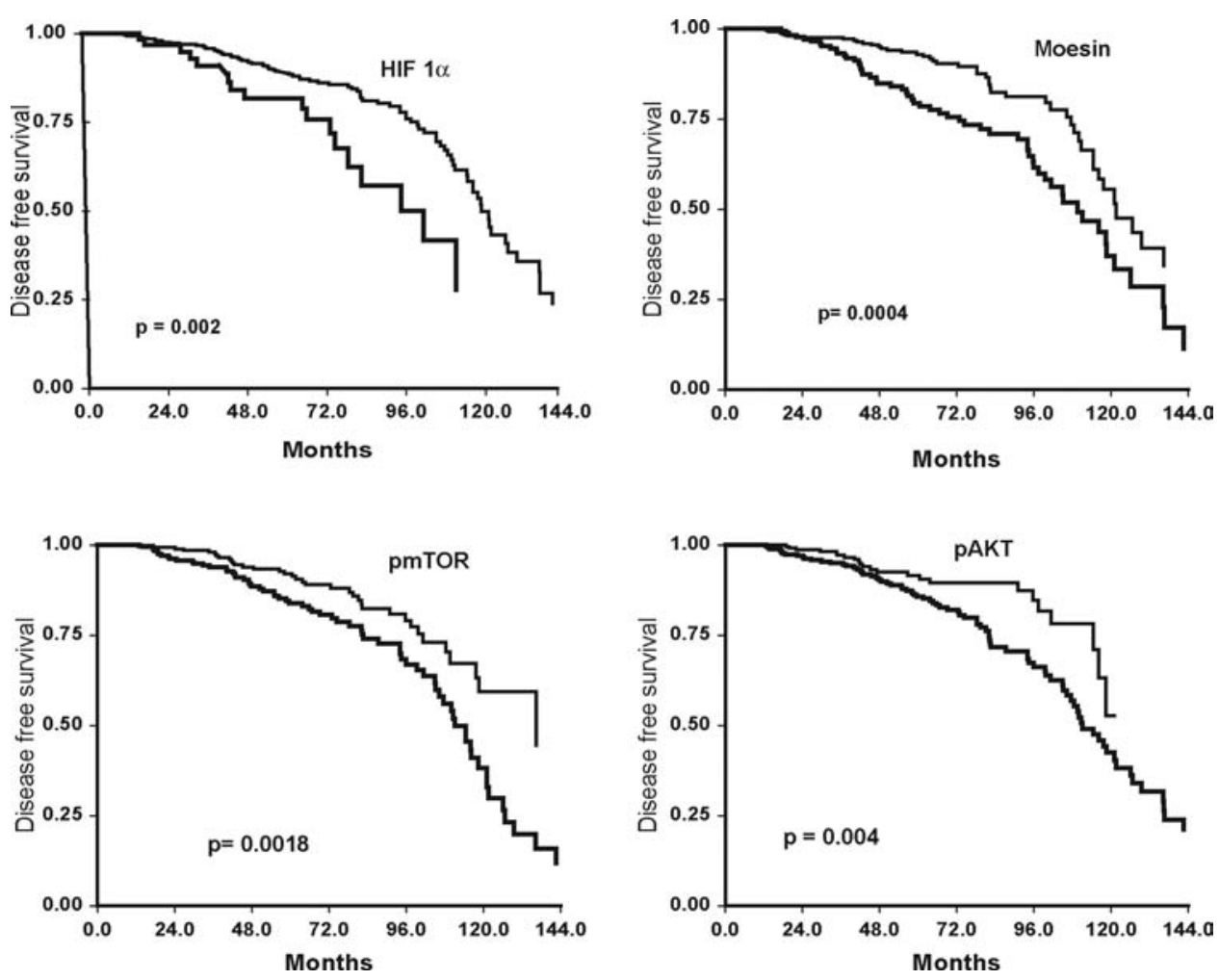

Figure 2. Kaplan-Meier curves (log-rank test) determining individual prognostic significance of markers (as shown for HIF-1 $\alpha$, Moesin, pmTOR and pAKT) quantitative scores in 572 node-negative breast carcinomas (TMA, quantitative immunochemical assays).

model for adverse outcome (logit) for the 10-marker signature (quantitative score/QS of individual 64 markers) was:

Logit: $-0.62602+3.2469 \mathrm{E}-02 \times(\mathrm{p} 4 \mathrm{E}-\mathrm{BP} 1 \mathrm{QS})+$ $0.19086 \times($ HIF-1 $\alpha$ QS $)+3.9232 \mathrm{E}-02 \times($ Moesin QS $)+$ 2.9267E-02 $\times(\mathrm{P} 21 \mathrm{QS})+7.1781 \mathrm{E}-02 \times(\mathrm{P} 27 \mathrm{QS})+$ 8.30815E-02 $\times($ pAKT QS $)+7.7037 \mathrm{E}-02 \times(\mathrm{PI} 3 \mathrm{~K} \mathrm{QS})+$ 7.4231E-02 x (pMAPKAPK QS) + $0.31909 \times($ pmTOR QS) + 4.973E-02 x (SHARP-2 QS).

This model estimates ' $\mathrm{B}$ ' for a specific group (in the present analysis the group of patients with metastases), where
$\operatorname{logit}(\mathrm{Y})=\mathrm{XB}$ and $(\mathrm{X})=$ densitometric quantitative score for each marker. To calculate the probability of classifying in the correct category of outcome, the logit is transformed using Prob $=\exp (-\operatorname{logit}) /[1+\exp (-\operatorname{logit})]$ or Prob $=\exp (-\mathrm{XB}) /$ $[1+\exp (-\mathrm{XB})]$.

Likewise for the ten-marker signature (quantitative scores of 61 markers, that is all 64 minus ER, PR and HER-2): Logit : $-0.50965+3.2708 \mathrm{E}-02 \times(\mathrm{p} 4 \mathrm{E}-\mathrm{BP} 1 \mathrm{QS})+0.18267 \times$ $($ HIF-1 $\alpha$ QS) + 3.7484E-02 $x$ (Moesin QS) + 4.1069E-02 $\mathrm{x}$ $(\mathrm{P} 21 \mathrm{QS})+8.4261 \mathrm{E}-02 \times(\mathrm{pAKT} \mathrm{QS})+7.8838 \mathrm{E}-02 \times(\mathrm{PI} 3 \mathrm{~K}$ 

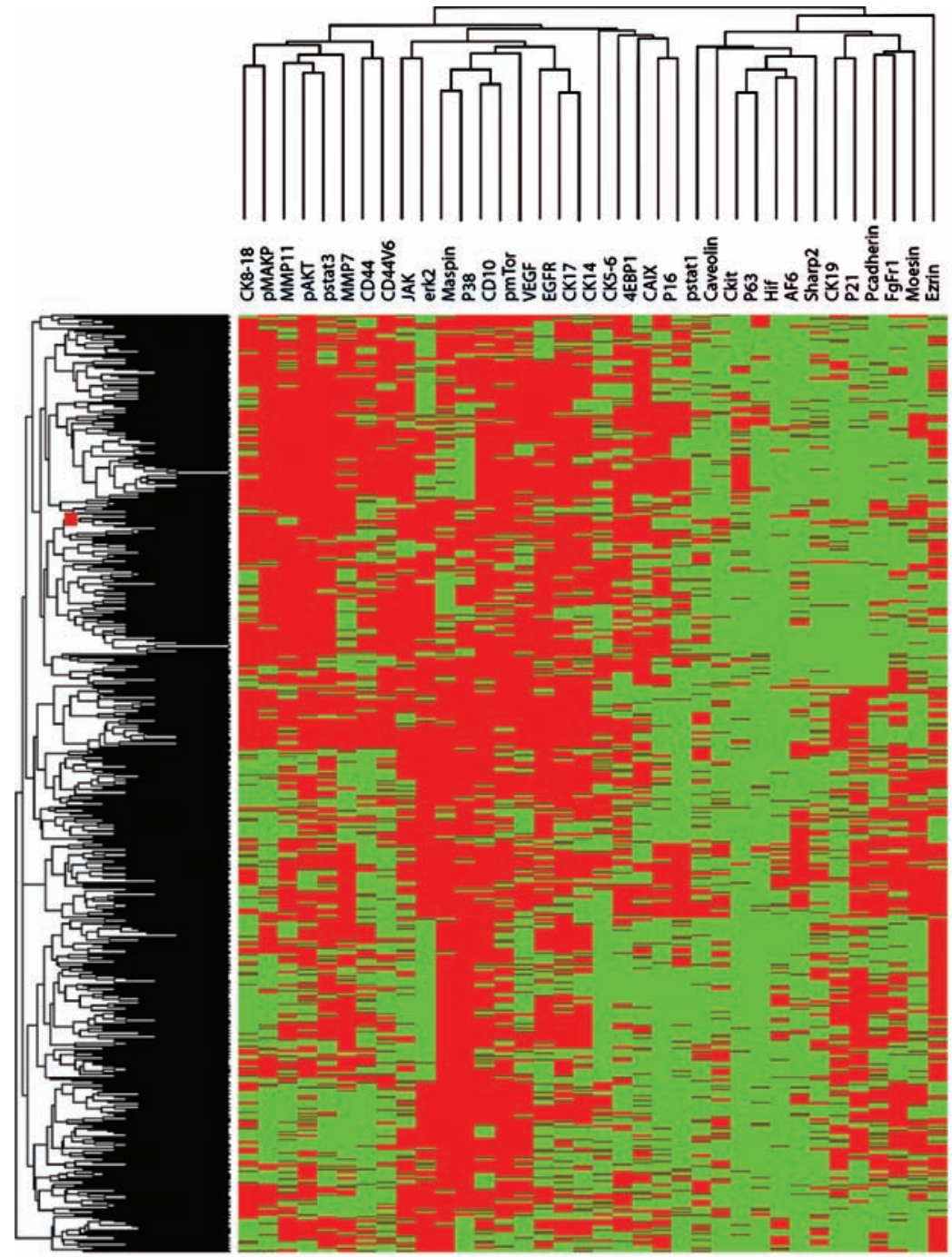

Figure 3. Supervised hierarchical clustering of the markers (excluding ER, PR and HER-2) with prognostic significance in the log-rank test, established with quantitative densitometry of immunohistochemical assays on TMA ( $\mathrm{n}=572$ patients with node-negative breast carcinomas) and quantitative score cut-points for each marker, as determined by log-rank test.

Table II. Prognostic predictive value of optimal combination of markers and groups of markers determined by logistic regression, evaluated by quantitative IHC in 572 node negative breast carcinomas.

Signatures $\quad$ Immunohistochemical markers

Logistic regression
$\%\left(^{\mathrm{a}}\right) \quad$ Surface under ROC curve

\begin{tabular}{llrl}
\hline $\begin{array}{l}\text { Optimal signature } \\
\text { (Independent of } \\
\text { ER, PR, HER-2) }\end{array}$ & PI3K, pmTOR, pMAPKAPK-2, SHARP-2, P21, & 91.6 & 0.95 \\
Angiogenesis & HIF-1 $\alpha$, Moesin, p4-BP-1, pAKT, P27 & & \\
Angiogenesis + & HIF-1 $\alpha$, VEGF, CD146, CD34, FGFR-1, CA-IX & 65 & 0.74 \\
signaling pathways & PI3K, pAKT, pMAPKAPK-2, pmTOR, P38 & 90.03 & 0.94 \\
& MAPKinase, p4E-BP-1, EIF4E, FOXO3a, FAK, & & \\
& JAK, FYN, STAT-1, STAT-3, SHARP-2, P42 & & \\
& MAPKinase, HIF-1 $\alpha$, VEGF, CD146, CD34, & \\
& FGFR-1, CA-IX & \\
\hline
\end{tabular}

aPercentages of well classified patients (series of 572 node negative patients with breast carcinoma, 102 months mean follow up); ${ }^{\mathrm{n}} \mathrm{n}=10$; ${ }^{\mathrm{c} n=24}$. 

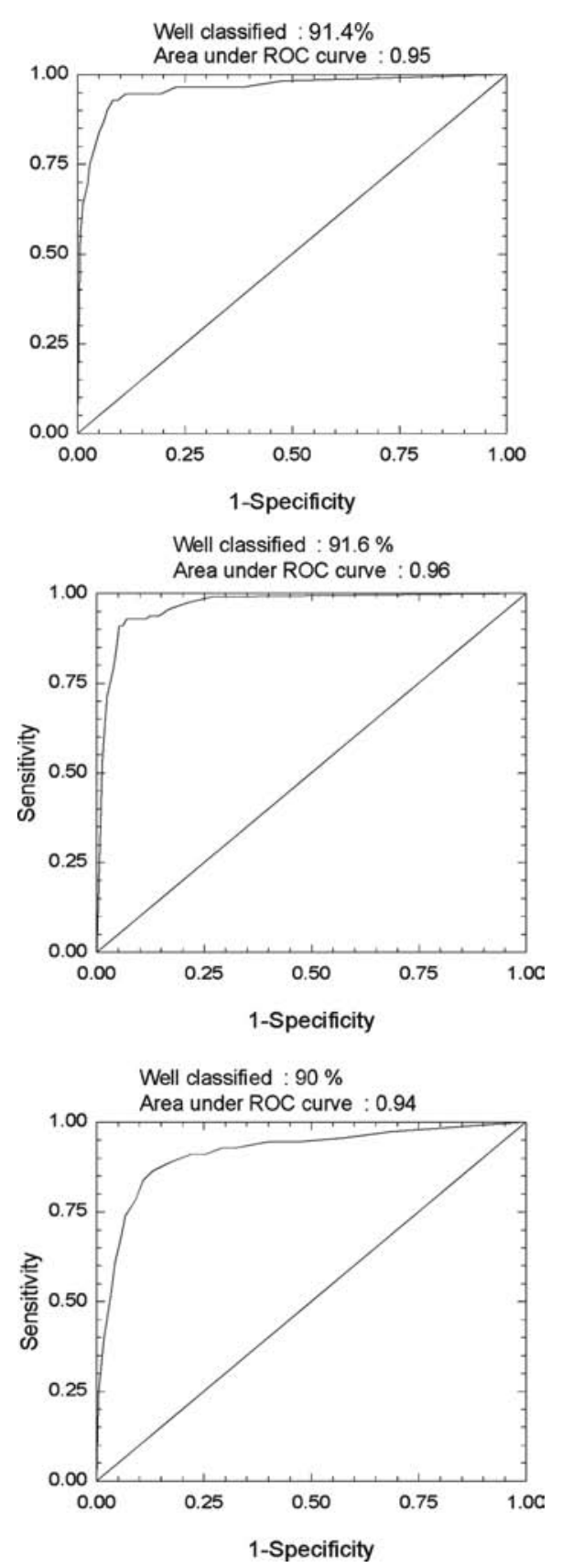

Figure 4. First and second steps of logistic regression and ROC curves determining the signature (PI3K, pmTOR, pMAPKAPK-2, SHARP-2, P21, HIF-1 $\alpha$, Moesin, p4EBP-1, pAKT and P27) that correctly classified nodenegative patients (91.4 and $90 \%$ top and bottom respectively in the category of favorable and unfavorable prognosis). A second regression assessed independently of ER, PR and HER-2 status also correctly classified $91.6 \%$ of the patients (middle). Quantitative immunohistochemical assays on TMA of 572 node-negative breast carcinomas.

$\mathrm{QS})+7.0824 \mathrm{E}-02 \times(\mathrm{pMAPKAPK} \mathrm{QS})+0.3126 \times(\mathrm{pmTOR}$ $\mathrm{QS})+4.4381 \mathrm{E}-02 \times($ SHARP2 QS $)+5.2845 \mathrm{E}-02 \times(\mathrm{P} 27 \mathrm{QS})$. and the probability was computed by the same procedure as indicated above.

When a shortened list of preselected markers was analysed, grouped into subsets according to their specific biological functions based on literature data, two other combinations of markers exhibited a similarly strong relevance for prediction of prognosis. Thus the association of markers of angiogenesis, or main signaling pathways properly classified $90 \%$ of the patients (sensitivity $89.19 \%$ well classified patients $99 / 111$, specificity $90.24 \%$ well classified patients $416 / 461$ ). But this signature included many more markers $(n=24)$ instead of 10 , to obtain a high predictive value (Table II).

\section{Discussion}

We used a high-throughput quantitative immunohistochemical procedure as previously reported $(42,43)$ to analyse samples from a large series of patients with node-negative breast carcinoma $(n=572)$, in order to identify an optimal combination of markers allowing the selection of patients who would not benefit from adjuvant chemotherapy.

Marker screening. No previous study has been reported that used this approach of quantitative immunocytochemical tumour profiling for prediction of prognosis in node-negative breast carcinomas, although some quantitative immunohistochemical assays have been reported for smaller sets of markers (17-21) with different study designs. Our selection of markers, mainly including a panel of molecules involved in tumour growth and progression, was based on a literature review and also upon our previous experience of their reliable and discriminative IHC in routine sections from frozen or fixed tissue and TMAs $(22-28,40,52,55)$. The final choice of antibodies, as noted previously $(42,43)$, thus relied on their commercial availability, their suitability for use on paraffinembedded archival material, their potential clinical relevance for breast cancer management, as reported in recent investigations on gene expression profiles (4-13), and previous IHC studies (29-39). This clearly implies that the signature proposed here may evolve as the number of the markers tested increases, but it is likely that it will be difficult to find a combination with significantly stronger sensitivity and specificity, than those described herein.

Most recent high-throughput immunohistochemical studies have focused on tumours of poor prognosis that currently lack tailored therapy, such as basal-like and triple-negative breast carcinomas, in order to identify new molecular targets for specific therapies $(37,38)$. In contrast, our study was designed to select patients with node-negative tumours having the most favorable prognosis, who would not require aggressive adjuvant chemotherapy. Other studies have similarly assessed gene expression profiling in node-negative tumours $(10,12,13)$, but IHC procedures are much easier to conduct, requiring sections of only 4 microns thick (40 microns for 10 markers) from formalin-fixed tissue in paraffin blocks remaining available after diagnosis. Procedures can be performed in 24-48 h in Pathology departments, and importantly are much more cost-effective than genomic tests (about tenfold cheaper).

Statistical analysis. Choosing cut-off points for positive staining of prognostic markers in semi-quantitative analyses is a major issue that must be addressed prior to attempting statistical analysis and correlation with the patient outcome in order for this methodology to be usable in routine clinical practice. In contrast, high-throughput quantification of immunoprecipitates by densitometry, using dedicated computerized devices properly and uniformly calibrated for immuno- 
histochemical detection with a large tumour series (TMAs), provides an excellent method for comparison of subsets of tumours in a given cohort. This method yields measurements appropriate for statistical analysis using continuous variables. Cut-point values of immunostaining can be determined according to log-rank tests for determination of prognostic values by splitting patients in a series into two categories or more, those with tumours expressing the markers above or below validated (45) thresholds predictive of disease-free survival. However, the use of cut-points has been criticized and a more sophisticated strategy can be proposed (44-47) that keeps continuous the values of quantitative scores measurements. According to this principle and recommendation, we applied this multivariable model for quantifying the expression of potential predictors of prognosis. Markers were quantitatively evaluated in TMA tissue sections by image analysis, using arbitrary units for densitometric measurements that are suitable for comparative studies of marker expression in variable clinical settings, particularly to correlate properly the expression of markers with the outcome variables. In this regard, using this multivariable fractional polynomial method $(44,46,47)$, we analysed the correlation between marker expression and patient outcome without dichotomising our tumour series into subsets by the use of a cut-point. In other words, all the 64 markers (and subsets of markers) were concomitantly analysed according a non-linear model, in order to obtain the best combination of a limited number of markers with optimal accuracy, sensitivity and specificity for prognosis prediction. In this manner, we found that a tenmarker signature (PI3K, pmTOR, pMAPKAPK-2, SHARP-2, P21, HIF-1 $\alpha$, Moesin, $4^{\mathrm{E} B P}$-1, pAKT and P27) was sufficient to correctly classify patients in $91.43 \%$ of the cases, independently of ER, PR and HER-2 status. However, validation of this signature is now required in prospective studies using routine sections of individual tumours.

Biological relevance. The markers included in the signature include mainly molecules involved in the main signaling pathways within abnormal tumour cells with altered cell machinery. Most of these markers have been individually reported as dysfunctional in tumours $(40,42,43)$ and described as potential targets for specific therapy. Interestingly, among those included in our ten-marker signature, some are involved in the mTOR pathway (PI3K, AKT, 4 $\left.4^{\mathrm{E}} \mathrm{BP}-1\right)$ and other signaling networks. The mTOR (mammalian Target Of Rapamycin) protein shows aberrant high activity in breast cancers, as well as other gynecological malignancies, which induces increased tumour cell metabolism and growth, and has been proposed as an interesting target for specific therapy. Phase I and II trials have shown that molecules such as the rapamycin analogues tensirolimus (CCI 799), everolimus (RAD CO1) and ARIAD (AP 23573), which specifically inhibit the mTOR protein, have significant antitumour activitya against gynecological cancers (48). Likewise, in breast cancers, molecules blocking mTOR activity increase sensitivity to anthracyclines and taxans (49) and show synergistic action with letrozole (50).

Overexpression of Moesin in breast carcinomas has recently been reported in basal-like carcinomas (35). It is therefore not surprising that Moesin is indicative of prognosis, in asso- ciation with the other markers of the signature that we have also identified in node-negative tumours that are associated with an unfavorable patient outcome, and so require more aggressive treatment.

HIF-1 $\alpha$ is a major transcriptional factor in nutrient stress signaling, and is crucial for the development of anticancer therapy (51). In a previous study (52), we have shown that expression of HIF-1 $\alpha$ in usual tissue sections of breast carcinoma was prognostically predictive in univariate analysis in node-negative tumours. HIF- $1 \alpha$ has been found to up-regulate mTOR through upstream mTOR activators including PI3K and AKT (53), suggesting that the effects of HIF- $1 \alpha$ on tumour cell metabolism and growth can be blocked through mTOR inactivation by PI3K and AKT inhibitors (54). HIF-1 $\alpha$ also mediates VEGF angiogenic machinery, acting on tumour neoangiogenesis through PI3K, AKT and other factors including the ras-MAPK pathways $(51,55)$. Blockage of VEGF by monoclonal antibodies or by anti-VEGF-R molecules such as sunitinib, sorafenib or vatalanib may reduce tumour growth due to overexpression of HIF- $1 \alpha$ in tumour cells (reviewed in 51,52,55).

In conclusion, using 1) a high-throughput procedure to profile 572 node-negative tumours in TMAs, 2) computerassisted densitometric quantification, 3) non-linear fractional polynomial logistic regression using continuous values of quantitative immunohistochemical variables to identify the combinations of a limited number of markers without any categorisation through pre-defined cut-points, we found a ten-marker signature that allowed correct classification of $91.6 \%$ of the patients, independently of hormone receptor and HER-2 status, and that particularly identified patients with low risk of early metastasis, who consequently should not require adjuvant chemotherapy.

\section{Acknowledgements}

This study was supported by a grant from the Institut National contre le Cancer - INCa/Canceropole and Conseil Régional Provence Alpes Côte d'Azur - AP-HM (Assistance Publique, Hôpitaux de Marseille).

\section{References}

1. Early Breast Cancer Trialists' Collaborative Group (EBCTCG): Effects of chemotherapy and hormonal therapy for early breast cancer on recurrence and 15-year survival: an overview of the randomised trials. Lancet 365: 1687-1717, 2005.

2. Goldhirsch A, Glick JH, Gelber RD, Coates AS, Thurlimann B, Senn HJ and Panel Members: Meeting highlights: international expert consensus on the primary therapy of early breast cancer. Ann Oncol 16: 1569-1583, 2005.

3. NCCN Clinical Practice Guidelines in Oncology: www.ncen.org, 2007.

4. Perou CM, Sorlie T, Eisen MB, Van de Rijn M, Jeffrey SS, Ree CA, Pollack JR, Ross DT, Johnsen H, Akslen LA, Fluge O, Pergamenschikov A, Williams C, Zhu SX, Lonning PE, Borresen-Dale AL, Brown PO and Botstein D: Molecular portraits of human breast tumours. Nature 406: 747-752, 2000.

5. Van de Vijver MJ, He YD, Van't Veer LJ, Dai H, Hart AA, Voskuil DW, Schreiber GJ, Peterse JL, Roberts C, Marton MJ, Parrish M, Atsma D, Witteveen A, Glas A, Delahaye L, van der Velde T, Bartelink H, Rodenhuis S, Rutgers ET, Friend SH and Bernards R: A gene-expression signature as a predictor of survival in breast cancer. N Engl J Med 347: 1999-2009, 2002. 
6. Van't Veer LJ, Dai H, Van't de Vijver MJ, He YD, Hart AA, Mao M, Peterse HL, Van der Kooy K, Marton MJ, Witteveen AT, Schreiber GJ, Kerkhoven RM, Roberts C, Linsley PS, Bernards R and Friend SH: Gene expression profiling predicts clinical outcome of breast cancer. Nature 415: 530-536, 2002.

7. Sorlie T, Tibshirani R, Parker J, Hastie T, Marron JS, Nobel A, Deng S, Johnsen H, Pesich R, Geisler S, Demeter J, Perou CM, Lonning PE, Brown PO, Borresen-Dale AL and Botstein D: Repeated observation of breast tumour subtypes in independent gene expression data sets. Proc Nat Acad Sci USA 100: 8418-8423, 2003.

8. Bertucci F, Finetti P, Rougemont J, Charafe-Jauffret E, Nasser V, Loriod B, Camerlo J, Tagett R, Tarpin C, Houvenaeghel G, Nguyen C, Maraninchi D, Jacquemier J, Houlgatte R, Birnbaum D and Viens P: Gene expression profiling for molecular characterization of inflammatory breast cancer and prediction of response to chemotherapy. Cancer Res 64: 8558-8565, 2004.

9. Pittman J, Huang E, Dressman H, Horng CF, Cheng SH, Tsou MH, Chen CM, Bild A, Iversen ES, Huang AT, Nevins JR and West M: Integrated modeling of clinical and gene expression information for personalized prediction of disease outcomes. Proc Natl Acad Sci USA 101: 8431-8436, 2004.

10. Chang HY, Nuyten DS, Sneddon JB, Hastie T, Tibshirani R, Sorlie T, Dai H, He YD, van't Veer LJ, Bartelink H, van de Rijn M, Brown PO and van de Vijver MJ: Robustness, scalability, and integration of a wound-response gene expression signature in predicting breast cancer survival. Proc Natl Acad Sci USA 102: 3738-3743, 2005

11. Paik S, Shak S, Tang G, Kim C, Baker J, Cronin M, Baehner FL, Walker MG, Watson D, Park T, Hiller W, Fisher ER, Wickerham DL, Bryant J, Wolmark N: A multigene assay to predict recurrence of tamoxifen-treated, node-negative breast cancer. N Engl J Med 351: 2817-2826, 2004.

12. Buyse M, Loi S, Van't Veer L, Viale G, Delorenzi M, Glas AM, d'Assignies MS, Bergh J, Lidereau R, Ellis P, Harris A, Bogaerts J, Therasse P, Floore A, Amakrane M, Piette F, Rutgers E, Sotiriou C, Cardoso F and Piccart MJ: Validation and clinical utility of a 70-gene prognostic signature for women with node-negative breast cancer. J Natl Cancer Inst 98: 11831192, 2006.

13. Wang Y, Klijn JG, Zhang Y, Sieuwerts AM, Look MP, Yang F, Talantov D, Timmermans M, Meijer-van Gelder ME, Yu J, Jatkoe T, Berns EM, Atkins D and Foekens JA: Gene-expression profiles to predict distant metastasis of lymph-node-negative primary breast cancer. Lancet 365: 671-679, 2005.

14. Dunkler D, Michiels S and Schemper M: Gene expression profiling: does it add predictive accuracy to clinical characteristics in cancer prognosis? Eur J Cancer 43: 745-751, 2007.

15. Michiels S, Koscielny S and Hill C: Prediction of cancer outcome with microarrays: a multiple random validation strategy. Lancet 365: 488-492, 2005.

16. Simon R, Radmacher MD, Dobbin K and McShane LM: Pitfalls in the use of DNA microarray data for diagnostic and prognostic classification. J Natl Cancer Inst 95: 14-18, 2003.

17. Camp RL, Chung GG and Rimm DL: Automated subcellular localization and quantification of protein expression in tissue microarrays. Nat Med 8: 1323-1327, 2002.

18. Emerson JW, Dolled-Filhart M, Harris L, Rimm DL and Tuck DP: Quantitative assessment of tissue biomarkers and construction of a model to predict outcome in breast cancer using multiple imputation. Cancer Inform 7: 29-40, 2009.

19. Chung GG, Zerkowski MP, Ghosh S, Camp RL and Rimm DL: Quantitative analysis of estrogen receptor heterogeneity in breast cancer. Lab Invest 87: 662-669, 2007.

20. Moeder CB, Giltnane JM, Harigopal M, Molinaro A, Robinson A, Gelmon K, Huntsman D, Camp RL and Rimm DL: Quantitative justification of the change from $10 \%$ to $30 \%$ for human epidermal growth factor receptor 2 scoring in the American Society of Clinical Oncology/College of American Pathologists guidelines: tumour heterogeneity in breast cancer and its implications for tissue microarray based assessment of outcome. J Clin Oncol 25: 5418-5425, 2007.

21. Pozner-Moulis S, Cregger M, Camp RL and Rimm DL: Antibody validation by quantitative analysis of protein expression using expression of Met in breast cancer as a model. Lab Invest 87: 251-260, 2007

22. Charpin C, Dales JP, Garcia S, Carpentier S, Djemli A, Andrac L Lavaut MN, Allasia C and Bonnier P: Tumour neoangiogenesis by CD31 and CD105 expression evaluation in breast carcinoma tissue microarrays. Clin Cancer Res 10: 5815-5819, 2004.
23. Charpin C, Garcia S, Bonnier P, Martini F, Andrac L, Horschowski N, Lavaut MN and Allasia C: bcl-2 automated and quantitative immunocytochemical assays in breast carcinomas: correlation with 10-year follow-up. J Clin Oncol 16: 2025-2031, 1998.

24. Charpin C, Garcia S, Bouvier C, Devictor B, Andrac L, Choux R, Lavaut MN and Allasia C: Automated and quantitative immunocytochemical assays of CD44v6 in breast carcinomas. Hum Pathol 28: 289-296, 1997.

25. Charpin C, Garcia S, Bouvier C, Martini F, Andrac L, Bonnier P, Lavaut MN and Allasia C: CD31/PECAM automated and quantitative immunocytochemical assays in breast carcinomas: correlation with patient follow-up. Am J Clin Pathol 107: 534-541, 1997.

26. Charpin C, Vielh P, Duffaud F, Devictor B, Andrac L, Lavaut MN, Allasia C, Horschowski N and Piana L: Quantitative immunocytochemical assays of P-glycoprotein in breast carcinomas: correlation to messenger RNA expression and to immunohistochemical prognostic indicators. J Natl Cancer Inst 86: 1539-1545, 1994.

27. Garcia S, Dales JP, Charafe-Jauffret E, Carpentier-Meunier S, Andrac-Meyer L, Jacquemier J, Andonian C, Lavaut MN, Allasia $\mathrm{C}$, Bonnier $\mathrm{P}$ and Charpin $\mathrm{C}$ : Overexpression of c-Met and of the transducers PI3K, FAK and JAK in breast carcinomas correlates with shorter survival and neoangiogenesis. Int J Oncol 31: 49-58, 2007.

28. Garcia S, Dales JP, Jacquemier J, Charafe-Jauffret E, Birnbaum D, Andrac-Meyer L, Lavaut MN, Allasia C, Carpentier-Meunier S, Bonnier $\mathrm{P}$ and Charpin-Taranger $\mathrm{C}$ : c-Met overexpression in inflammatory breast carcinomas:automated quantification on tissue microarrays. Br J Cancer 96: 329-335, 2007.

29. Makretsov NA, Huntsman DG, Nielsen TO, Yorida E, Peacock M, Cheang MC, Dunn SE, Hayes M, van de Rijn M, Bajdik C and Gilks CM: Hierarchical clustering analysis of tissue microarray immunostaining data identifies prognostically significant groups of breast carcinoma. Clin Cancer Res 10: 6143-6151, 2004

30. Nielsen TO, Hsu FD, Jensen K, Cheang M, Karaca G, Hu Z, Hernandez-Boussard T, Livasy C, Cowan D, Dressler L, Akslen LA, Ragaz J, Gown AM, Gilks CB, van de Rijn M and Perou CM: Immunohistochemical and clinical characterization of the basal-like subtype of invasive breast carcinoma. Clin Cancer Res 10: 5367-5374, 2004.

31. Ginestier C, Charafe-Jauffret E, Bertucci F, Eisinger F, Geneix J, Bechlian D, Conte N, Adelaide J, Toiron Y, Nguyen C, Viens P, Mozziconacci MJ, Houlgatte R, Birnbaum D and Jacquemier J: Distinct and complementary information provided by use of tissue and DNA microarrays in the study of breast tumour markers. Am J Pathol 161: 1223-1233, 2002.

32. Jacquemier J, Ginestier C, Rougemont J, Bardou VJ, CharafeJauffret E, Geneix J, Adelaide J, Koki A, Houvenaeghel G, Hassoun J, Maraninchi D, Viens P, Birnbaum D and Bertucci F: Protein expression profiling identifies subclasses of breast cancer and predicts prognosis. Cancer Res 65: 767-779, 2005.

33. Charafe-Jauffret E, Ginestier C, Monville F, Finetti P, Adelaide J, Cervera N, Fekairi S, Xerri L, Jacquemier J, Birnbaum D and Bertucci F: Gene expression profiling of breast cell lines identifies potential new basal markers. Oncogene 25: 2273-2284, 2006.

34. Livasy CA, Karaca G, Nanda R, Tretiakova MS, Olopade OI, Moore DT and Perou CM: Phenotypic evaluation of the basallike subtype of invasive breast carcinoma. Mod Pathol 19: 264-271, 2006.

35. Charafe-Jauffret E, Monville F, Bertucci F, Esterni B, Ginestier C, Finetti P, Cervera N, Geneix J, Hassanein M, Rabayrol L, Sobol H, Charpin C, Xerri L, Viens P, Birnbaum D and Jacquemier $\mathrm{J}$ : Moesin expression is a marker of basal breast carcinomas. Int J Cancer 121: 1779-1785, 2007.

36. Laakso M, Tanner M, Nilsson J, Wiklund T, Erikstein B, Kellokumpu-Lehtinen P, Malmstrom P, Wilking N, Bergh J and Isola J: Basoluminal carcinoma:a new biologically and prognostically distinct entity between basal and luminal breast cancer. Clin Cancer Res 12: 4185-4191, 2006.

37. Da Silva L, Clarke C and Lakhani SR: Demystifying basal-like breast carcinomas. J Clin Pathol 60: 1328-1332, 2007.

38. Reis-Filho JS and Tutt AN: Triple negative tumours: a critical review. Histopathology 52: 108-118, 2008.

39. Rakha EA, El-Sayed ME, Green AR, Paish EC, Lee AH and Ellis IO: Breast carcinoma with basal differentiation: A proposal for pathology definition based on basal cytokeratin expression. Histopathology 50: 434-438, 2007. 
40. Garcia S, Dales JP, Charafe-Jauffret E, Carpentier-Meunier S, Andrac-Meyer L, Jacquemier J, Andonian C, Lavaut MN, Allasia C, Bonnier P and Charpin C: Poor prognosis in breast carcinomas correlates with increased expression of targetable CD146 and c-Met and with proteomic basal-like phenotype. Hum Pathol 38: 830-841, 2007.

41. Jacquemier J, Padovani L, Rabayrol L, Lakhani SR, PenaultLlorca F, Denoux Y, Fiche M, Figueiro P, Maisongrosse V, Ledoussal V, Martinez Penuela J, Udvarhely N, Udvarhely N, El Makdissi G, Ginestier C, Geneix J, Charafe-Jauffret E, Xerri L, Eisinger F, Birnbaum D and Sobol H: Typical medullary breast carcinomas have a basal/myoepithelial phenotype. J Pathol 207: 260-268, 2005.

42. Charpin C, Secq V, Giusiano S, Carpentier S, Andrac L, Lavaut MN, Allasia C, Bonnier P and Garcia S: A signature predictive of disease outcome in breast carcinomas, identified by quantitative immunocytochemical assays. Int J Cancer 124: 2124-2134, 2009.

43. Charpin C, Giusiano S, Secq V, Carpentier S, Andrac L, Lavaut MN, Allasia C, Bonnier P and Garcia S: Quantitative immunocytochemical profiling predictive of early outcome of disease in triple-negative breast carcinomas. Int J Oncol 34: 983-993, 2009.

44. Royston P, Douglas G and Sauerbrei A: Dichotomising continuous predictors in multiple regression: a bad idea. Stat Med 25: 127-141, 2006.

45. Altman DG, Lausen B, Sauerbrei W and Schumacher M: Dangers of using 'optimal' cutpoints in the evaluation of prognostic factors. J Natl Cancer Inst 86: 829-835, 1994.

46. Von Elm E, Altman DG, Egger M, Pocock SJ, Gotzsche PC and Vandenbroucke JP: The strengthening the reporting of observational studies in epidemiology (STROBE) statement: Guidelines for reporting observational studies. Lancet 370: 1453-1457, 2007.

47. Von Elm E, Altman DG, Egger M, Pocock SJ, Gotzsche PC and Vandenbroucke JP: The strengthening the reporting of observational studies in epidemiology (STROBE) statement: Guidelines for reporting observational studies. J Clin Epidem 61: 344-349, 2008.
48. Darb-Esfahani S, Faggad A, Noske, Weichert W, Buckendahl AC, Muller B, Budczies J, Roske A, Dietel M and Denker C: Phospho-mTOR and phospho-4EBP1 in endometrial adenocarcinoma :association with stage and grade in vivo and link with response to rapamycin treatment in vitro. $\mathrm{J}$ Cancer Res Clin Oncol 135: 933-941, 2009.

49. Rao RD, Buckner JC and Sarkaria JN: Mammalian target of rapamycin (mTOR) inhibitors as anti-cancer agents. Curr Cancer Drug Targets 4: 621-635, 2004.

50. Boulay A, Rudloff J, Ye Y and Zumstein-Mecker S: Dual inhibition of mTOR and estrogen receptor signaling in vitro induces cell death in models of breast cancer. Clin Cancer Res 11: 5319-5328, 2005

51. Pouyssegur J, Dayan F and Mazure NM: Hypoxia signaling in cancer and approaches to enforce tumour regression. Nature 441: 437-443, 2006.

52. Dales JP, Garcia S, Meunier-Carpentier S, Andrac-Meyer L, Haddad O, Lavaut MN, Allasia C, Bonnier P and Charpin C: Overexpression of hypoxia-inducible factor HIF-1alpha predicts early relapse in breast cancer: retrospective study in a series of 745 patients. Int J Cancer 116: 734-739, 2005.

53. Gort EH, Groot AJ, Derks van de Ven TLP, van der Groep P, Verlaan I, van Laar T, van Diest PJ, vand der Wall E and Shvartz A: Hypoxia-inducible factor-1a expression requires PI 3-kinase activity and correlates with Akt1 phosphorylation in invasive breast carcinomas. Oncogene 1-5, 2006

54. Helczynska K, Larsson AM, Holmquist Mengelbier L, Bridges E, Fredlund E, Borgquist S, Landberg G, Pahlman S and Jirstrom K: Hypoxia-inducible factor-2a correlates to distant recurrence and poor outcome in invasive breast cancer. Cancer Res 68: 9212-9220, 2008

55. Dales JP, Garcia S, Carpentier S, Andrac L, Ramuz O, Lavaut MN, Allasia C, Bonnier P and Taranger-Charpin C: Prediction of metastasis risk (11 year follow-up) using VEGF-R1, VEGF-R2, Tie-2/Tek and CD105 expression in breast cancer ( $\mathrm{n}=905)$. Br J Cancer 90: 1216-1221, 2004. 